\title{
Propagation of Swine Hemagglutinating Encephalomyelitis Virus and Pseudorabies Virus in Dorsal Root Ganglia Cells
}

\author{
Yoko HARA ${ }^{1)}$, Rie HASEBE ${ }^{2)}$, Yuji SUNDEN ${ }^{1)}$, Kenji OCHIAI ${ }^{1)}$, Eiichi HONDA ${ }^{3)}$, Yoshihiro SAKODA ${ }^{4)}$ and \\ Takashi UMEMURA ${ }^{1) *}$ \\ ${ }^{1)}$ Laboratory of Comparative Pathology, Graduate School of Veterinary Medicine, Hokkaido University, N18 W9, Sapporo 060-0818, \\ ${ }^{2)}$ Department of Prion Diseases, Graduate School of Veterinary Medicine, Hokkaido University, N18 W9, Sapporo 060-0818, \\ ${ }^{3)}$ Laboratory of Veterinary Microbiology, Department of Veterinary Medicine, Tokyo University of Agriculture and Technology, Fuchu, \\ Tokyo 183-8509 and ${ }^{4)}$ Laboratory of Microbiology, Graduate School of Veterinary Medicine, Hokkaido University, N18 W9, Sapporo \\ 060-0818, Japan
}

(Received 6 November 2008/Accepted 17 December 2008)

ABSTRACT. Swine hemagglutinating encephalomyelitis virus (HEV) causes encephalomyelitis or vomiting and wasting disease in suckling piglets. Neurotoropism of the virus has been demonstrated in previous in vivo studies. In the present study, we investigated the infectivity and propagation of HEV in comparison with those of pseudorabies virus (PRV), another neurotropic virus, using dorsal root ganglia cells of newborn mice containing nerve cells and non-neuronal cells. HEV infected nerve cells but did not infect non-neuronal cells, whereas PRV infected both cell types. By using cytoskeletal inhibitors, it was suggested that propagation of HEV and PRV within and among nerve cells depended on microtubules and intermediate filaments of nerve cells, indicating that the viruses may be transported between the cell body and axonal terminals of neurons by fast axonal flow.

KEY WORDS: cytoskeleton, pseudorabies virus, swine hemagglutinating encephalomyelitis virus, virus propagation.

J. Vet. Med. Sci. 71(5): 595-601, 2009

Swine hemagglutinating encephalomyelitis virus (HEV) belongs to the order Nidoviracles, family Coronaviridae, genus Coronavirus. The virus was first isolated in Canada from the brains of suckling piglets [25], and causes encephalomyelitis or vomiting and wasting disease in suckling piglets $[6,25]$. In previous in vivo studies using piglets and mice, HEV has been suggested to invade the central nervous system via the peripheral nervous system (neural spread) [2, $11,25,32,33]$. However, the neural spread of HEV has not been demonstrated by in vitro studies.

In our previous report, we demonstrated that neural spread of pseudorabies virus (PRV), a neurotropic alphaherpesvirus, in cultured nerve cells obtained from dorsal root ganglia (DRG) of newborn mice required the integrity of microtubules and intermediate filaments of the cells, whereas neural spread of influenza A was independent of microtubule integrity [20]. In this paper, we compared neurotropism and the roles of neuronal cytoskeletal components in the neural spread of HEV with those of PRV using cultured nerve cells and non-neuronal cells from DRG of newborn mice.

\section{MATERIALS AND METHODS}

Viruses: The HEV 67N strain was first isolated from the nasal cavities of apparently healthy feeder pigs in 1972 in the United States. This virus was propagated in FS-L3 cells [27]. Pseudorabies virus, also known as Aujeszky's disease

\footnotetext{
* Correspondence to: Umemura, T., Laboratory of Comparative Pathology, Graduate School of Veterinary Medicine, Hokkaido University, N18 W9, Sapporo 060-0818, Japan.

e-mail: umemura@vetmed.hokudai.ac.jp
}

virus or suid herpes virus 1, belongs to the subfamily Alphaherpesvirinae of the family Herpesviridae. Pseudorabies virus strain Yamagata-S 81 (PRV) was the first Japanese isolate from piglets [13]. This virus was propagated in cloned porcine kidney (CPK) cells.

$D R G$ cell culture: DRG of the spinal cords of newborn ICR/Jcl mice (2-4 days old) were dissociated by incubation with $1 \mathrm{mg} / \mathrm{ml}$ collagenase (Sigma-Aldrich, St. Louis, MO, U.S.A.) at $37^{\circ} \mathrm{C}$ for $30 \mathrm{~min}$. Dissociated cells were resuspended at a concentration of 50,000 nerve cells (about 100 ganglia) per $\mathrm{ml}$ in maintenance medium (MM) comprised of Eagle's minimal essential medium (Sigma-Aldrich) supplemented with $10 \%$ heat-inactivated fetal bovine serum (Biofluids, Rockville, MD, U.S.A.), $50 \mathrm{U} / \mathrm{ml}$ penicillin (GIBCO, Gaithersburg, NY, U.S.A.) and $50 \mu \mathrm{g} / \mathrm{ml}$ streptomycin (GIBCO). Collagen-coated $35 \mathrm{~mm}$ dishes with central 14 $\mathrm{mm}$ glass coverslips (Matsunami Glass, Osaka, Japan) were seeded with $100 \mu \mathrm{l}$ of the cell suspension. Cells were then incubated in MM with $10 \mu \mathrm{M}$ 5-fluoro-2'-deoxyuridine (Sigma-Aldrich) and $40 \mathrm{nM} 2.5 \mathrm{~S}$ nerve growth factor (Invitrogen, Carlsbad, CA, U.S.A.) in a $5 \% \mathrm{CO}_{2}$ atmosphere at $37^{\circ} \mathrm{C}$. The medium was changed every $2-3$ days. After 710 days of incubation, when an axonal network of nerve cells had formed, dishes were used for the experiments. In each dish, non-neuronal cells were admixed with nerve cells.

Infection of cultured DRG cells with HEV and PRV: Cultured DRG cells on the $14 \mathrm{~mm}$ coverslip were inoculated with either HEV at $10^{6.7} \mathrm{TCID}_{50} / \mathrm{ml}$ or PRV at $10^{4.37} \mathrm{TCID}_{50} /$ $\mathrm{ml}$ in $100 \mu \mathrm{l}$ of $\mathrm{MM}$ and incubated for $1 \mathrm{hr}$ at $37^{\circ} \mathrm{C}$. The viral suspension was removed and cells were washed three times with MM, then incubated in MM for 24, 48 and $60 \mathrm{hr}$. 
At least three samples were examined for each time point. Mock-infected DRG cells were used as a negative control.

Cytoskeletal interference and viral propagation in cultured DRG cells: Nocodazole (NOC; Sigma-Aldrich) was used for the disruption of microtubules, acrylamide (ACR; Sigma-Aldrich) for the perturbation of intermediate filaments and cytochalasin D (CYD; Sigma-Aldrich) for the disruption of microfilaments. Full-grown nerve cells with axonal networks were prepared on $14 \mathrm{~mm}$ coverslips in 35 mm dishes. The cultured DRG cells were treated with NOC at 1,5 and $10 \mu \mathrm{M}$ or ACR at 1,2 and $3 \mathrm{mM}$ for $23 \mathrm{hr}$ before infection. In the case of CYD, DRG cells were treated at 1 , 2.5 and $5 \mu \mathrm{M}$ for $2 \mathrm{hr}$ before infection. After that the cells were inoculated with either $\mathrm{HEV}$ at $10^{6.7} \mathrm{TCID}_{50} / \mathrm{ml}$ or PRV at $10^{4.37} \mathrm{TCID}_{50} / \mathrm{ml}$ in $100 \mu \mathrm{l}$ of MM and incubated for $1 \mathrm{hr}$ at $37^{\circ} \mathrm{C}$. The inoculum was then removed by washing with MM three times and MM was applied with each drug. At 2 hr post inoculation (p.i.), the inoculum of CYD was then removed by washing with MM three times and MM was applied without drugs and incubated until $48 \mathrm{hr}$ p.i. At the withdrawal of each drug, cells were washed with MM three times. At $48 \mathrm{hr}$ p.i., infected DRG cells in all dishes were fixed for morphological examination. Stock solutions of NOC (10 mM) and CYD (1 mM) in DMSO and ACR (1 M) in double-distilled water were prepared and diluted to the final concentration in MM. The maximum concentrations of inhibitors were chosen to maximize the drug effects without any apparent cytotoxic effect on cell morphology. CYD concentrations of more than $5 \mu \mathrm{M}$ caused detachment of cultured DRG cells. The intermediate and minimum concentrations were used to confirm the effect of inhibitors. Controls were treated with an equal volume of DMSO or double-distilled water. At least three dishes were used for each treatment. Student's $t$-test was used to assess the statistical significance of differences between the groups $(P<0.01$ and $P<0.05)$. Each experiment was performed at least three times.

Immunocytochemical analysis: DRG cells were fixed with 4\% paraformaldehyde (Merck, Darmstadt, Germany) for $10 \mathrm{~min}$ and permeabilized with $0.2 \%$ Triton X-100 (Sigma-Aldrich) for $5 \mathrm{~min}$. Nonspecific binding of antibodies was blocked by incubation with $2 \%$ bovine serum albumin (Sigma-Aldrich) for $30 \mathrm{~min}$. Newly prepared mouse antiserum against HEV and rabbit antiserum against PRV (a gift from Dr. E. Ono) was used for the detection of viral antigens. A mouse monoclonal anti-tubulin $\beta$ III isoform antibody (Chemicon International, Temecula, CA, U.S.A.), rabbit polyclonal anti-tubulin $\beta$ III isoform antibody (Abcam, Cambridge, UK), mouse anti-neurofilament-M\&H phosphorylated form antibody (Chemicon International), rabbit polyclonal anti-pan neurofilament antibody (BIOMOL International, Plymouth Meeting, PA, U.S.A.) and Alexa Fluor 488-conjugated phalloidin (Molecular Probes, Eugene, OR, U.S.A.) were used to visualize microtubules, neurofilaments and microfilaments, respectively. Alexa Fluor 488-conjugated anti-rabbit IgG donkey serum (Molecular Probes), Alexa Fluor 488-conjugated anti- mouse IgG donkey serum (Molecular Probes), Alexa Fluor 555-conjugated anti-mouse IgG donkey serum (Molecular Probes) and Alexa Fluor 555-conjugated anti-rabbit IgG donkey serum (Molecular Probes) were used as secondary antibodies. Hoechst 33258 (Wako Pure Chemical Industries, Osaka, Japan) was used for nuclear staining. Analyses were performed with an Olympus Fluoview FV500 confocal laser scanning microscope (Olympus, Tokyo, Japan) and Fluoview software version 5.0 (Olympus). For calculating the infectivity of each virus, images of 5 fields were viewed at random, and the number of antigen-positive DRG cells was counted. At least three dishes were used for each treatment. Student's $t$-test was used to assess the statistical significance of differences between the groups. Each experiment was repeated at least three times.

All the experiments using experimental animals were conducted in accordance with the policies of the Animal Care and Use Committee, Graduate School of Veterinary Medicine, Hokkaido University.

\section{RESULTS}

Infectivitiy of viruses in nerve cells in cultured DRG: The percentage of antigen-positive nerve cells in the $14 \mathrm{~mm}$ coverslip was counted at each time point. Nerve cells were always stained with the anti-tubulin $\beta$ III antibody in our cultured DRG cells. The time courses of propagation of both viruses in DRG nerve cells were similar and cells that were antigen-positive for both viruses increased time dependently. In HEV infection, viral antigen-positive nerve cells were not detected at 0 and $24 \mathrm{hr}$ p.i. (Fig. 1a, A, B) but after that they sharply increased. At $48 \mathrm{hr}$ p.i. (Fig. 1a, C), about $85 \%$ of the nerve cells were viral antigen-positive and this figure reached $90 \%$ at $60 \mathrm{hr}$ p.i. (Fig. 1a, D). The viral antigens of HEV first appeared at the cell periphery of nerve cells and then extended to the whole cytoplasm of the cells (Fig. 1a, C). After that, the viral antigens were detected in the axons (Fig. 1a, D). In PRV infection, viral antigen-positive nerve cells were not detected at $0 \mathrm{hr}$ p.i. (Fig. 1a, E) and slowly increased until $24 \mathrm{hr}$ p.i. (Fig. 1a, F). After that, the number of positive cells sharply increased from 24 to $48 \mathrm{hr}$ p.i. At 48 hr p.i., $100 \%$ of the cells were viral antigen-positive (Fig. 1a, G, 1b). The viral antigens appeared first in nuclei or perinuclear regions (Fig. 1a, F), and then moved to periphery of the neuronal cell bodies (Fig. 1a, G). After that, viral antigen-positive granules appeared in the axons (Fig. 1a, H). No severe damage due to virus infection was observed in the nerve cells except for mild swelling of cell bodies (Fig. 1a).

Infectivity of viruses in non-neuronal cells in cultured $D R G$ : In our cultured DRG cells, non-neuronal cells coexisted with nerve cells. The non-neuronal cells were not stained by the anti- tubulin $\beta$ III antibody. These cells were spindle-shaped with fusiform nuclei or irregularly shaped with flattened nuclei. The non-neuronal cells were not infected by $\mathrm{HEV}$ but $34 \%$ of them became PRV antigenpositive at $48 \mathrm{hr}$ p.i. (Fig. 2a, b). 


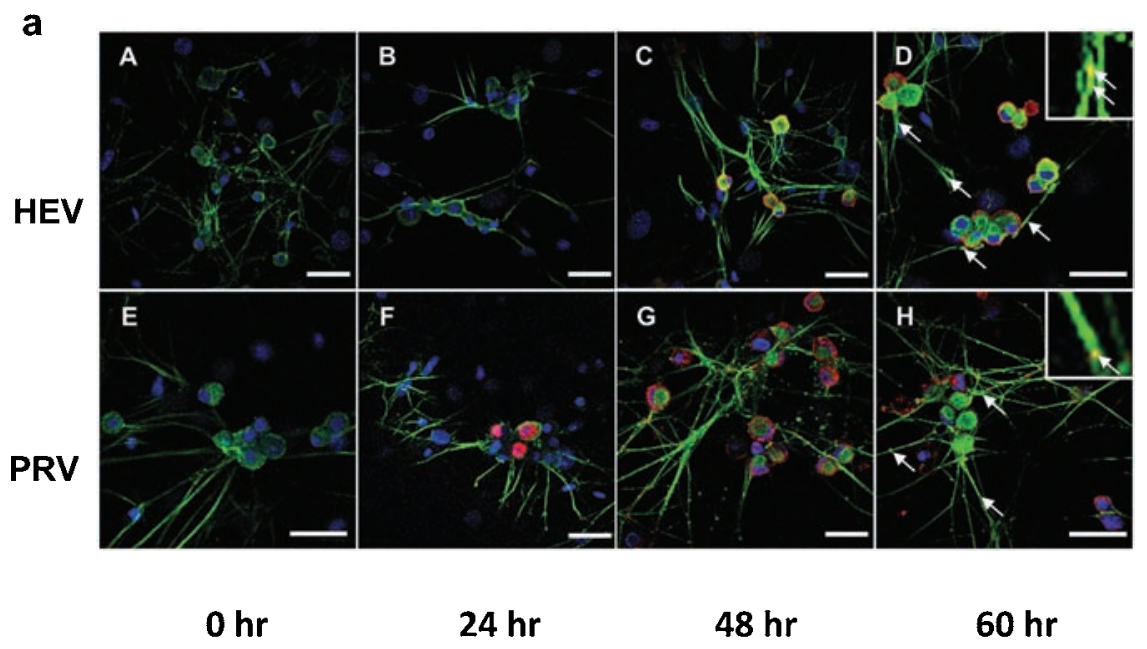

b

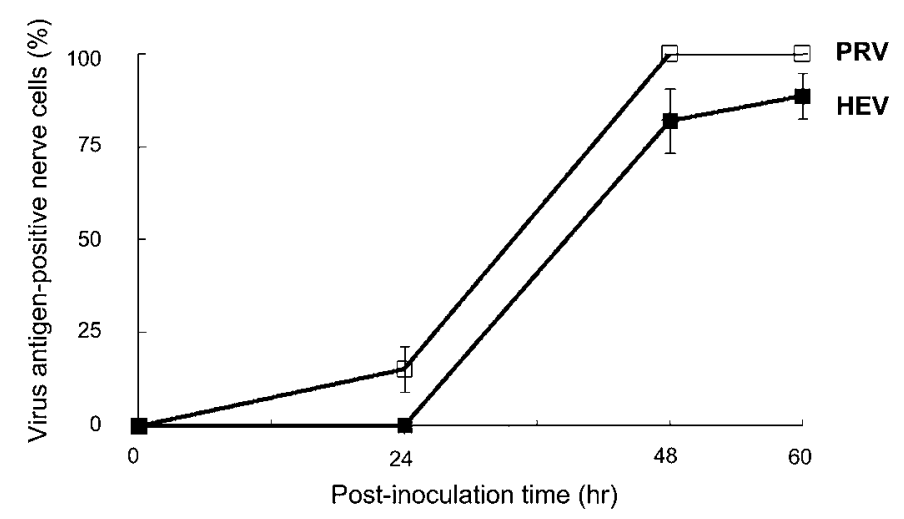

Fig. 1. Confocal images of cultured nerve cells and percentages of virus antigen-positive cells after HEV and PRV infection. a, Confocal images of nerve cells immunostained for viral antigens (red), tubulin $\beta$ III (green) and nerve cell nuclei (blue). Viral antigens are HEV (A-D) and PRV (E-H). Insets in D and $\mathrm{H}$ are higher magnification of axons. Arrows indicate viral antigens in the axons (yellow). Bars $=100 \mu \mathrm{m}$. b, Percentages of virus antigen-positive nerve cells. Closed squares are HEV and open squares are PRV. Each value is expressed as the mean \pm SD.

Effects of cytoskeletal perturbation on viral propagation: The cytoskeletal morphology was not modified by viral infection without drug treatment, and each inhibitor specifically affected the morphology of the targeted cytoskeletal component. The nerve cells untreated with NOC had confocal images of granular to fibrillary tubulin staining. Nerve cells treated with NOC lost these characteristics depending on the concentration of the inhibitor, and only a few fine linear microtubules were observed at the maximum concentration $(10 \mu \mathrm{M})$. The number of PRV-positive cells was reduced drastically with an increase of the NOC concentration in the medium and PRV-positive nerve cells were scarcely observed in dishes treated with $10 \mu \mathrm{M}$ NOC. In contrast, the number of HEV-positive nerve cells gradually decreased with the increase of the NOC concentration (Fig. 3a). Neurofilaments exhibited fibrillary staining in control nerve cells. With ACR treatment, neurofilament protein characteristically accumulated at the axon terminals and this change became evident with the increased ACR concentrations. Cells that were antigen-positive for HEV or PRV decreased with increased ACR concentrations (Fig. 3b) and viral antigens gradually decreased in the axons depending on the concentration. The morphology of actin filaments was not affected by CYD treatment, and the percentages of antigen-positive nerve cells were not significantly different from the control for both viruses (Fig. 3c).

\section{DISCUSSION}

The cultured newborn mouse DRG cells used in our study were composed of nerve cells and non-neuronal cells. Our findings were consistent with previous studies on cultured 


\section{a}

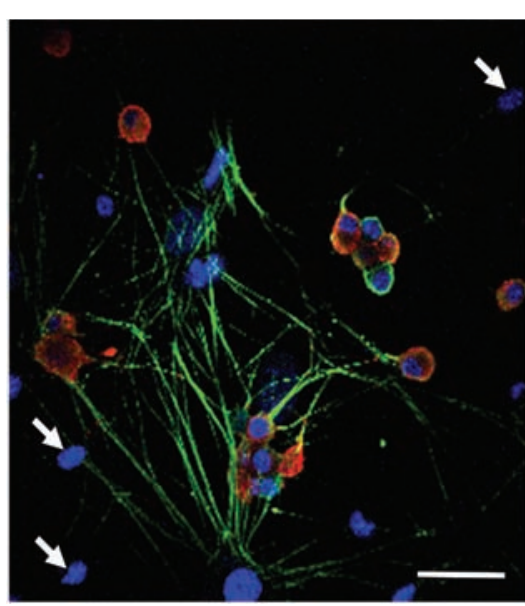

HEV

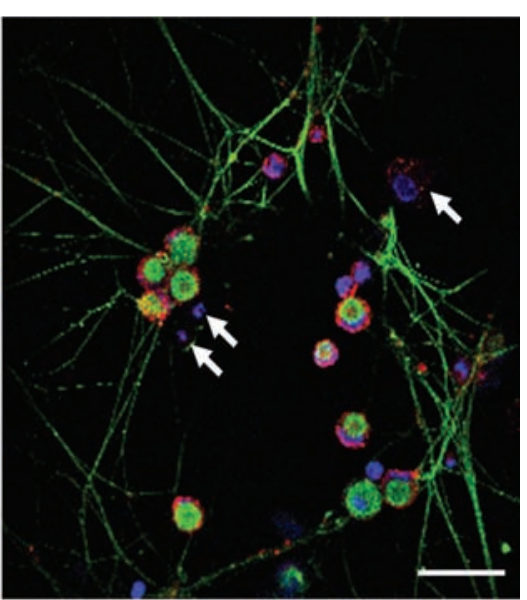

PRV

b

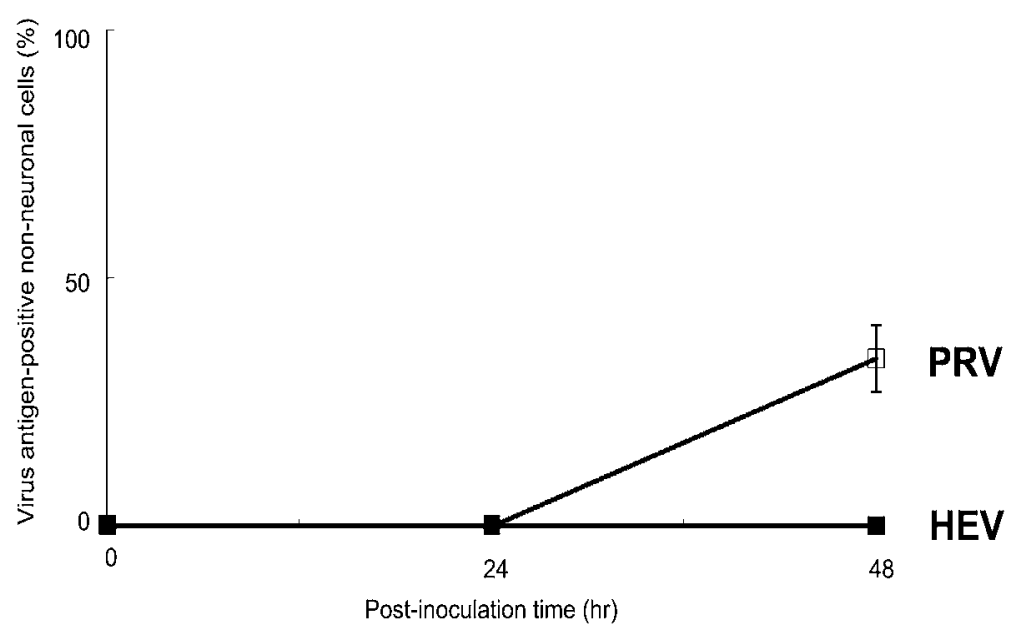

Fig. 2. Confocal images and percentages of virus antigen-positive non-neuronal cells in cultured DRG cells infected with HEV and PRV. a, Non-neuronal DRG cells are immunostained for viral antigens (red), tubulin $\beta$ III (green) and nuclei (blue). Nerve cells are immunostained for tubulin $\beta$ III and non-neuronal cells are not immunostained for tubulin $\beta$ III. Arrows indicate non-neuronal cells. Bars $=100 \mu \mathrm{m}$. b, Percentages of virus antigenpositive non-neuronal cells. Closed squares are HEV and open squares are PRV. Each value is expressed as the mean $\pm \mathrm{SD}$.

mouse DRG cells $[1,8,10,29,30]$. Nerve cells were identified by their characteristic spherical cell bodies, fine axonal projections, small spherical nuclei, and immunohistochemical staining with the neuron-specific tubulin $\beta$ III antibody. Non-neuronal cells were composed of 2 kinds of cells: spindle-shaped cells with fusiform nuclei and irregularly shaped cells with flattened nuclei. Based on the morphology of these non-neuronal cells, the former were considered to be Schwann cells and the latter fibroblasts [1, 10]. In the present study, PRV infected nerve cells and nonneuronal cells, but HEV antigen was found only in nerve cells. These in vitro findings were consistent with previous in vivo studies in which PRV antigens were found in astrocytes and nerve cells [3, 9], whereas HEV particles could be found in nerve cells but were not detected in glial cells and infiltrating cells [11, 12, 23]. Based on these in vivo and in 
a

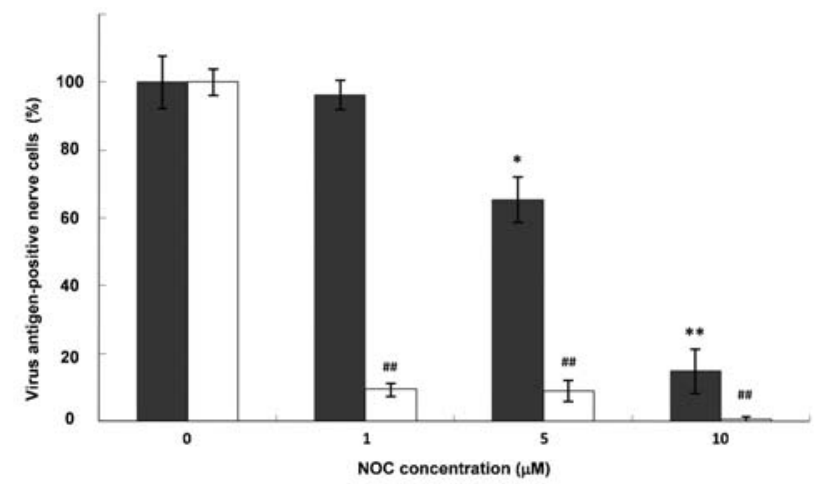

b

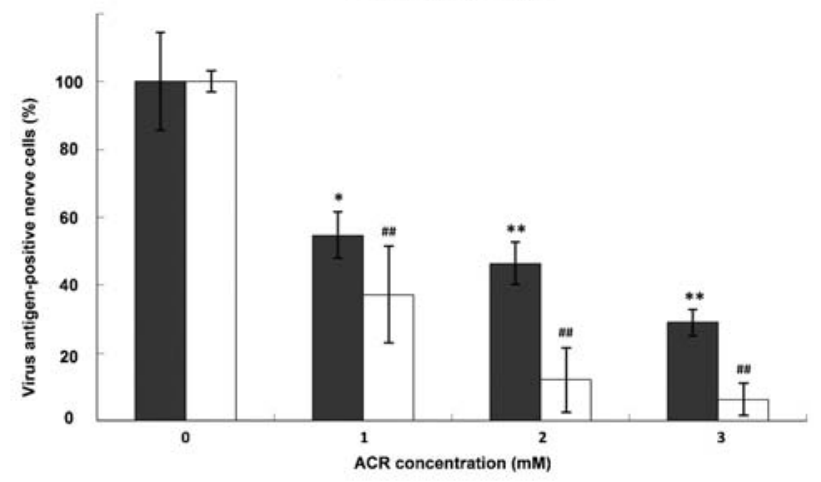

c

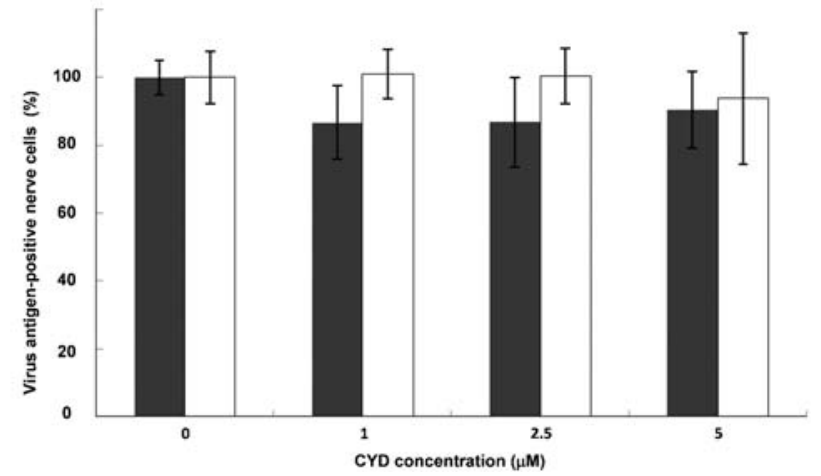

Fig. 3. Effects of cytoskeletal perturbation on viral propagation in cultured nerve cells treated with the cytoskeletal inhibitors indicated at the bottom of each panel. Nerve cells were infected with HEV (black columns) or PRV (white columns). Results are expressed as the percentage of antigen-positive nerve cells for each concentration of the cytoskeletal inhibitors. Values of the control group are adjusted to $100 \%$. Columns and vertical bars show mean \pm SD. ${ }^{* *} p<0.01$, \#\# $p<0.01$ and $* p<0.05$ vs. controls.

vitro findings, infectivity of HEV may be more strictly restricted to nerve cells than PRV and rabies virus, for which non-neuronal cells may support viral entry and replication [19].

HEV antigens localized to the periphery of nerve cells in the early stage of infection and then spread to the entire cytoplasm and axon terminals. In general, coronaviruses bind to specific cell surface receptors via the surface projectional glycoproteins and then replicative cycles occur in the cytoplasm [21-24]. Complete virions assemble to the rough endoplasmic reticulum or Golgi apparatus [15, 24, 29]. In a previous electron microscopic study on HEV encephalitis in piglets, viral particles were observed in the cytoplasm of infected neurons; most of the particles were found close to the cytoplasmic membrane and some were confined to the endoplasmic reticulum or Golgi structures [24]. Accordingly, the localization of viral antigens in HEV-infected nerve cells in our in vitro study was consistent with the process of viral propagation proposed in previous in vivo studies. 
To understand the relation between HEV propagation and neuronal cytoskeletal components (microtubules, intermediate filaments, and microfilaments), cultured nerve cells disrupted selectively for these components with specific inhibitors were exposed to HEV and PRV. NOC is a reversible mitotic inhibitor that binds the fast-growing ends of microtubules and prevents monomer addition $[4,16]$. ACR is a water-soluble vinyl monomer and has been used as an intermediate filament disruption agent [7]. ACR inhibits neurotransmission and membrane turnover in nerve terminals $[17,18]$. CYD is a small, naturally occurring organic molecule and destabilizes microfilaments by binding to the fast-growing end of the filaments [5]. In this study, viral propagation of PRV in nerve cells was inhibited by NOC and ACR treatment in a dose-dependent manner by the inhibitors, whereas CYD treatment did not affect the propagation of the PRV. These results were consistent with previous reports [14, 20,31] and suggest that PRV depends on microtubules of nerve cells to transport its capsid-tegument structure to the nucleus using fast axonal flow [14, 26, 28, 31]. The intermediate filament disruption by ACR suggested that PRV propagation depends on intermediate filaments of nerve cells for viral assembly and/or membrane fusion at synapses [20]. PRV has been reported not to interact with microfilaments [14, 31]. We used maximally $5 \mu \mathrm{M}$ CYD in the present study but the disruption of microfilaments in the nerve cells was not morphologically apparent [20]. It is difficult to discuss the role of microfilaments in the propagation of both PRV and HEV. Interactions of HEV with the cellular cytoskeleton have not been reported, but previous reports on the localization of viral antigens in $\mathrm{HEV}$-infected neurons and the general propagation process of coronaviruses suggest that HEV uses microtubules and intermediate filaments in transporting viral endocytic vesicles to the Golgi apparatus and/or rough endoplasmic reticulum $[4,16]$, and in viral assembly and/or membrane fusion at synapses. Although the magnitude of the inhibitory effects on viral propagation was less prominent in HEV, disruption of the cytoskeletal components by inhibitors similarly affected the propagation of HEV and PRV in the present study. Therefore, the mode of viral propagation within and among nerve cells may be similar for HEV and $\mathrm{PRV}$, and the two viruses may be transported between the cell body and axon terminals of neurons by fast axonal flow. The mode of neural spread was distinctive from that of influenza A virus [20].

ACKNOWLEDGMENTS. We are grateful to Dr. E. Ono, Laboratory of Biomedicine, Center of Biomedical Research, Graduate School of Medical Sciences, Kyushu University for donating antiserum against pseudorabies virus. This work was supported by a Grant-in-Aid for Scientific Research (B: 19380171) from the Ministry of Education, Culture, Sports, Science and Technology of Japan and the Program of Founding Research Centers for Emerging and Reemerging Infectious Disease, MEXT Japan.

\section{REFERENCES}

1. Andersen, P. L., Doucette, J. R. and Nazarali, A. J. 2003. A novel method of eliminating non-neuronal proliferating cells from cultures of mouse dorsal root ganglia. Cell. Mol. Neurobiol. 23: 205-210.

2. Andries, K. and Pensaert, M. B. 1980. Immunofluorescence studies on the pathogenesis of hemagglutinating encephalomyelitis virus infection in pigs after oronasal inoculation. Am. J. Vet. Res. 41: 1372-1378.

3. Card, J. P., Rinaman, L., Schwaber, J. S., Miselis, R. R., Whealy, M. E., Robbins, A. K. and Enquist, L. W. 1990. Neurotropic properties of pseudorabies virus: uptake and transneuronal passage in the rat central nervous system. J. Neurosci. 10: 1974-1994.

4. Cheung, H. T. and Terry, D. S. 1980. Effects of nocodazole, a new synthetic microtubule inhibitor, on movement and spreading of mouse peritoneal macrophages. Cell. Biol. Int. Rep. 4: 1125-1129.

5. Cooper, J. A. 1987. Effects of cytochalasin and phalloidin on actin. J. Cell Biol. 105: 1473-1478.

6. Cutlip, R. C. and Mengeling, W. L. 1972. Lesions induced by hemagglutinating encephalomyelitis virus strain $67 \mathrm{~N}$ in pigs. Am. J. Vet. Res. 33: 2003-2009.

7. Eckert, B. S. 1985. Alteration of intermediate filament distribution in PtK1 cells by acrylamide. Eur. J. Cell Biol. 37: 169174.

8. Enquist, L. W., Tomishima, M. J., Gross, S. and Smith, G. A. 2002. Directional spread of an -herpesvirus in the nervous system. Vet. Microbiol. 86: 5-16.

9. Field, H. J. and Hill, T. J. 1974. The pathogenesis of pseudorabies in mice following peripheral inoculation. J. Gen. Virol. 23: 145-157.

10. Fleming, J., Ginn, S. L., Weinberger, R. P., Trahair, T. N., Smythe, J. A. and Alexander, I. E. 2001. Adeno-associated virus and lentivirus vectors mediate efficient and sustained transduction of cultured mouse and human dorsal root ganglia sensory neurons. Hum. Gene Ther. 12: 77-86.

11. Hirano, N., Nomura, R., Tawara, T. and Tohyama, K. 2004. Neurotropism of swine haemagglutinating encephalomyelitis virus (coronavirus) in mice depending upon Host age and route of infection. J. Comp. Pathol. 130: 58-65.

12. Hirano, N., Haga, S., Sada, Y. and Tohyama, K. 2001. Susceptibility of rats of different ages to inoculation with swine haemagglutinating encephalomyelitis virus (a coronavirus) by various routes. J. Comp. Pathol. 125: 8-14.

13. Itakura, C., Nakatsuka, J. and Goto, M. 1981. An incidence of pseudorabies (Aujeszky's disease) in piglets in Japan. Nippon Juigaku Zasshi 43: 923-927.

14. Kaelin, K., Dezélée, S., Masse, M. J., Bras, F. and Flamand, A. 2000. The UL25 protein of pseudorabies virus associates with capsids and localizes to the nucleus and to microtubules. $J$. Virol. 74: 474-482.

15. Koga, D. and Ushiki, T. 2006. Three-dimensional ultrastructure of the Golgi apparatus in different cells: high-resolution scanning electron microscopy of osmium-macerated tissues. Arch. Histol. Cytol. 69: 357-374.

16. Lee, J. C., Field, D. J. and Lee, L. L. 1980. Effects of nocodazole on structures of calf brain tubulin. Biochemistry 19: 62096215.

17. LoPachin, R. M. 2004. The changing view of acrylamide neurotoxicity. Neurotoxicology 25: 617-630.

18. LoPachin, R. M., Ross, J. F. and Lehning, E. J. 2002. Nerve 
terminals as the primary site of acrylamide action: a hypothesis. Neurotoxicology 23: 43-59.

19. Lycke, E. and Tsiang, H. 1987. Rabies virus infection of cultured rat sensory neurons. J. Virol. 61: 2733-2741.

20. Matsuda, K., Shibata, T., Sakoda, Y., Kida, H., Kimura, T., Ochiai, K. and Umemura, T. 2005. In vitro demonstration of neural transmission of avian influenza A virus. J. Gen. Virol. 86: $1131-1139$.

21. Mengeling, W. L. and Cutlip, R. C. 1972. Experimentally induced infection of newborn pigs with hemagglutinating encephalomyelitis virus strain 67N. Am. J. Vet. Res. 33: 953956.

22. Mengeling, W. L., Boothe, A. D. and Ritchie, A. E. 1972. Characteristics of a coronavirus (strain $67 \mathrm{~N}$ ) of pigs. Am. J. Vet. Res. 33: 297-308.

23. Meyvisch, C. and Hoorens, J. 1978. An electron microscopic study of experimentally-induced HEV encephalitis. Vet. Pathol. 15: 102-113.

24. Nermut, M. V. and Steven, A. C. 1987. Coronaviridae. pp. 173-183. In: Animal Virus Structure (Zuckerman, A. J. ed.), Elsevier, Amesterdam.

25. Pensaert, M. B. and Andries, K. 1986. Hemagglutinating Encephalomyelitis Virus Infection, pp. 310-315. In: Diseases of Swine, 6th ed. (Leman, A. D., Straw, B., Glock, R. D., Mengeling, W. L., Penny, R. H. C., Scholl, E. eds.), Iowa State University Press, Iowa.

26. Ploubidou, A. and Way, M. 2001. Viral transport and the cytoskeleton. Curr. Opin. Cell Biol. 13: 97-105.

27. Sasaki, I., Kazusa, Y., Shirai, J., Taniguchi, T. and Honda, E. 2003. Neutralizing test of hemagglutinating encephalomyelitis virus (HEV) in FS-L3 cells cultured without serum. J. Vet. Med. Sci. 65: 381-383.

28. Sodeik, B. 2000. Mechanisms of viral transport in the cytoplasm. Trends Microbiol. 8: 465-472.

29. Sommer, E. W., Kazimierczak, J. and Droz, B. 1985. Neuronal subpopulations in the dorsal root ganglion of the mouse as characterized by combination of ultrastructural and cytochemical features. Brain Res. 346: 310-326.

30. Tennyson, V. M. and Gershon, M. D. 1975. Light and electron microscopy of dorsal root, sympathetic, and enteric ganglia. pp. 121-155. In: Peripheral Neuropathy, 2nd ed., vol. 1 (Dyck, P. J., Thomas, P. K., Griffin, J. W., Low, P. A. and Poduslo, J. F. eds.), Saunders, London.

31. Tomishima, M. J., Smith, G. A. and Enquist, L. W. 2001. Sorting and transport of alpha herpesviruses in axons. Traffic 2: 429-436.

32. Yagami, K., Hirai, K. and Hirano, N. 1986. Pathogenesis of haemagglutinating encephalomyelitis virus (HEV) in mice experimentally infected by different routes. J. Comp. Pathol. 96: 645-657.

33. Yagami, K., Izumi, Y., Kajiwara, N., Sugiyama, F. and Sugiyama, Y. 1993. Neurotropism of mouse-adapted haemagglutinating encephalomyelitis virus. J. Comp. Pathol. 109: 21-27. 